O artigo aborda os determinantes históricos e os fundamentos epistemológicas que edificarama noção de "criança normal", advinda do campo científico da modemidade. Analisa, também, os efeitos dessa conceppção ao ser inconporada às práticas educacionais, scbretudb por meio das teorias psicológicas. Disate, ainda, os impasses vividos pelas equipes intercisciplinares, compostas por profissionais das áreas de saúdee educação, que atendem às crianças com diferentes problenáticas, ao tentarem respander às questões "o que é uma criança?", "como se desenvolvem as psicopatologias da infância?", "oque se trata, em uma criança?" Na conclusão, disaute a função do psicanal ista em uma atuação no campo interdiscipl inar de modb que seja asseguradb à criança um lugar desujeito.

Infância; psicanálise; práticas seciais

THE CONSTRUCTIONOF CHILDHOOD: SCIENTIFC KNOWLEDGES AND SOCIAL PRACTICES

In thepresent article it has been disassed the historical deteminats and the epistenological bases that constructed the issue abat "homal dilld", came from the modem scientificfield. Mbreover, ithasbeen arlyzed the effects of this conception when it is inconporated by theed cational practices, mostly thragh thepsychological theories. he alsopreseted the dallenges experiencedby the interctisciplinary graps composed withprofessionals of the heal thandedrational areas, which foas their work on dhildren withdifferest diffiaulties, aiming to solve the followingquestions: "hrat is adrild"?", "how the dritdrood"s psychquathologies are develqued?" "What is it treated in a child?" To conclune, it hasbeencisaussed the analyst's fundions in the schooling field, inawey that the individal's place canbeassired. childhood; psychoanalysis; social practices

\section{A CONSTRUÇÃO DA INFÂNCIA : ENTRE OS SABERES CIENTÍFICOS E AS PRÁTICAS SOCIAIS ${ }^{1}$}

\author{
Viviane Neves Legnani \\ Sandra Francesca Conte de Almeida
}

$V_{1}$ -se, na sociedade atual, uma crise ocasionada pela dil luição dos grandes discursos da modernidade. No que diz respeito ao campo da ciência, tem-se como conseqüência desta crise inúmeros questionamentos que causam uma avidez pelo conhecimento do próprio conhecimento.

Indagações de natureza epistemológica têm também atravessado as sistematizaçães sobre a infância, e, embora ainda se tenham poucas prooulçães que focal izem tais questões, o foco desses estudos atém-se a uma avaliação crítica da proposta principal do empreendimento modemo, qual seja,

Doutora em Psicologia pela UnB, psicanalista, professora do curso de Psicologia da Universidade

Católica de Brasília.

- Doutora em Ciências da Educação e diplomada em Psicologia Escolar pela Universidade René Descartes, Paris V (Sorbonne), membro analista do Percurso Psicanalítico de Brasília, professora do Programa de Pós-Graduação stricto sensu em Psicologia da Universidade Católica de Brasília e professora aposentada da UnB. 
de que o conhecimento científico seria propulsor de uma humanização das práticas sociais voltadas para o segmento infantil.

Vorcaro (1999) esclarece que na modemidade a criança cumpre a função de permitir à civilização a sustentação do ideal de seus ancestrais. Desde o século XIX e principalmente no século XX, houve uma confluência dos discursos médico e psicológico para viabil izar a proposta de educação laica e igual itária vol tada para as crianças, objetivando, com tal empreendimento educativo, o ancoramento de uma ampla reforma social. Assim, tem-se, hoje, uma representação da infância que, necessariamente, passa pela "criança escolar".

A concepção de que a representação da infância é construída, nos diversos contextos sociais, pelos diferentes disarrsos que incidem sobre essa etapa da vida remete ao clássico História social da criança e da família (Ariès, 1981) .

De acordo com Cauvilla (1999) , o trabalho desse historiador possibil itou o encontro com o par di lemático natureza-cultura e representa ummarco historiográfico por trazer para a discussão, na contemporaneidade, o tema da constituição da infância. Como efeito desse trabalho, passou-se a ter a visão de que essa fase do desenvolvimento é marcada pela cultura, sendo uma dessas marcas aquela que define a condição de infantil.

O historicismo de Ariès (1981) produziu efeitos significativos na psicologia do desenvolvimento, ocasionando um redimensionamento teórico/metodológico na área, pois contribuiu com um aporte crítico em relação à tônica das primeiras produções e sistematizações do conhecimento nesse campo, as quais enfatizavam a naturalidade do desenvolvimento da criança como um processo linear e contínu.

Em uma perspectiva também histórica, Castro (1992, 1996) traz vários elementos que convidam a uma análise epistemológica dessa área do conhecimento psicológico. De acordo com as proposições da autora, esse campo legitimou-se e autorizou-se a partir de um discurso sobre a infância, de cunho "cientificamente comprovado", pelo qual a psicologia do desenvolvimento articulou-se a uma "política de verdades", proposta pela ciência moderna. Nesta perspectiva, preocupou-se, sobretudo, em traduzir o paradigma da dbjetividade, neutralidade e racionalização no âmbito de suas sistematizações. Os pontos que respaldam a argumentação de Castro (1996) podem ser assim resumidos:

- o projeto da modemidade apoiou-se na visão de progresso, e todas as produçães científicas atrelaram-se ao ideário de "evolução" . A parte que coube à psicologia do desenvolvimento foi ratificar a representação da infância como uma etapa de vida perpas- 
sada pela imaturidade, que se transformaria ao longo do desenvolvimento, até atingir a plenitude da razão representativa da idade adulta. Deste modo, o processo de desenvolvimento passou a ser sistematizado como uma seqüência ordenada de um progressivo aperfeiçoamento;

- o caráter universal izante foi garantido por uma quase total negação da participação do contexto sócio-histórico no processo de desenvolvimento, bem como pela afirmação enfática da participação do biológico nesse processo, pois tal ênfase, ao contrário da primeira, garante a idéia do "aspecto natural" do arso da vida e, por conseguinte, é mais adequada para respaldar as teorias que dizem "a verdade" sobre o humano, pois se baseiam na "natureza humana" e em seus postulados e explicações;

- por fim, atrelada ao ideário de progresso e de evolução do ser humano e apoiando-se na universalização das etapas do desenvolvimento, essa área de saber respondeu, desde seus primórdios, às demandas de intervenção, controle e regulação social dos comportamentos, com base em categorizações advindas das teorias psicológicas. Construiu, a partir de classificações e mensuraçães das condutas, padrões para se medir as funções intelectuais e as aptidões e, passo seguinte, construiu as representações de deficiência, incapacidade, defasagem e imaturidade para designar a infância. Edificou, assim, a concepção de criança normal, em uma perspectiva que se apóia sobre um mecanismo de minimização das diferenças entre os sujeitos e maximização das semelhanças, a qual trouxe, em seu ceme, uma proposta de normatização e adequação dessa etapa do ciclo vital.

Em suma, o escopo das produções da psicologia do desenvolvimento esteve, desde sempre, comprometido com o projeto da modemidade. Totalmente imersa nesta proposta científica, essa área do saber psicológico desconsiderou o efeito que esse conhecimento normatizador teria sobre as sujeitos.

Uma questão importante que se impõe, a partir dessas disaussões, é situar o contexto histórico e alltural que possibilitau a emergência dessa racionalidade e autoridade epistêmica em suas teorizações sobre a infância, pois, cono se sabe, a instauraçãa de uma área de saber faz-se, dialeticamente, mediante a permissão de um determinado contexto social.

O recorte histórico proposto por Julien (2000) é elucidativo para se pensar o porquê de a sociedade modema outorgar o lugar de autoridade aos especialistas, ao longo do século XX. O autor destaca que o início desse processo deu-se na disjunção entre o público e o privado, que se fez nos laços da conjugalidade e parentalidade, durante a modemidade. Ou seja, o privado, nessa 
época, tomou-se o lugar de primazia das laças conjugais e o público, - lugar dos laças parentais, gperando-se aí uma nuptura com o que vigorava na sociedade antiga.

Essa nova clivagem ancorou-se no declínio da imagem social do pai, que não mais conseguirá efetivar seu poder e tê-lo reconhecido entre seus pares da comunidade, em razão de não ter mais condições de perpetuar, para os de sua linhagem, sua tradição e patrimônio.

Desse modo, a partir do declínio das laças sociais nas comunidades, a conjugalidade que, anteriormente, instaurava-se no registro do público passa para o domínio privado. Até então as escolhas dos casais eram feitas pela autoridade patere pelo viés da semelhança: mesmas crenças religiosas, educação, costumes, etc. A partir do ingresso na vida em sociedade, e do conseqüente declínio da autoridade patema, as escolhas dos futuros parceiros passam para o campo da intimidade. Consolida-se aí o espaço privado para a conjugalidade.

Um outro efeito desse fenômeno é o da "extimidade" parental, conforme assinala Julien (2000) . Passa a vigorar, no ideário no século $\mathrm{XX}$, que o bem-estar das crianças e de suas vidas futuras depende do "ninho familiar", o qual se constrói no registro da intimidade. Instaura-se aí, porém, um paradoxo, qual seja, a idéia de que a educação das crianças possa ser deixada, simplesmente, ao arbítrio das figuras parentais é questionada: "Em nome do bem do filho, vem, então, tomar lugar sob figuras diversas, um ter- 
ceiro social: o professor, a pediatra, apsicóloga, aassistentesocial, ojuiz de menores, o juiz de varas de família" (Julien, 2000, p. 15) .

No que diz respeito à participação do saber médico no processo de construção da concepção de infância tecida nos últimos dois séculos, e de igual forma à do saber psicológico, também houve nesse discurso científico uma vinculação ao projeto de reforma social em torno do avanço da ciência, conforme proposto pela modernidade. Formulando a premissa de que para se construir um futuro com menos transtomos sociais deveria haver uma preocupação maior com a infância, esse campo do saber passou a ocupar um lugar de destaque nas formações discursivas normativas das sociedades, principalmente nos séculos XIX e XX.

No Brasil, ainda no século XIX, conforme assinalam Pilotti e Rizzini (1995), Rizzini (1997) e Costa (1989), essa perspectiva reformista atrelou-se a uma proposta higienista que se adequou perfeitamente à expectativa do Estado no combate à insalubridade que se presentificava nos contextos urbanos. Desta forma, configurou-se um discurso único, de cunho científicopolitico, que foi responsável, desde então, pela dimensão de poder diferenciado do discurso médico. A medicina passou a ter, nesse cenário, um importante papel de controle social, pois o disarsso higienista ${ }^{2}$, que se voltava, inicialmente, para todas as classes sociais, gerou uma representação social acerca da família nuclear ideal que, por sua vez, passou a constituir-se como um padrão a ser seguido.

Nesse sentido, houve uma confluência do discurso médico com o discurso formulado pelo aparato jurídico-policial, e esta junção, de acordo com Rizzini (1997) , à medida que estabelecia um padrão familiar higienicamente saudável, ajudava na construção da representação acerca das famílias empobrecidas, que apareciam nessas formações discursivas como desajustadas e responsáveis pela delinqüência e abandono dos fillhos.

A institucionalização dos desviantes dos parâmetros de normalidade era admitida apenas em nome do caráter humanitário dessa prática. Muller (1999) discute um exemplo deste fato, a partir da inter-relação entre a psiquiatria infantil e os primórdios da educação especial, no contextobrasileiro.

A autora destaca o referido caráter humanitário como propulsor de uma série de medidas médicopedagógicas e o efeito dessas medidas na vida das denominadas creanças anormaes. Assim, a criação da primeira escola especial, no Brasil, em 1904, o Pavilhão Boumerville, teve como principal abjetivo o cambate à promiscuidade que advinha da mistura de adultos e crianças nos hospícios. A separação desses segmentos e um planejamento médico-pedagógico, inspirado na medicina francesa, para proporcionar uma educação moral às crianças, demonstram o propósito humanista dessa empreitada. Una autra face, porém, desse humanismo mostra-se quando se analisa a forma de ingres- 
so das crianças nesse atendimento, realizada mediante diagnóstico estabelecidb pelo médico perito da força policial.

Para Muller (1999), essa clara associação entre anormalidade e periculosidade demonstra que o principal critério adbtado para a intemação era, então, o risco à moral e à segurança pública que essas crianças supostamente representavam para o contexto social. Para a autora, essa articulação demonstra "que o perito e o médico, sob a legitimação de um discurso científico, substituíram o carrasco dos suplícios e se apoderaram dos meios de controle social, desmembrando as punições em outras estratégias, como a educação e o tratamento" (p. 16) .

Assim, historicamente, por meio de uma visão funcionalista, que pressupõe o funcionamento normal do organismo em termos de equilí́brio/desequilílorio, a prática médica constituiu-se como um mecanismo capaz de reconduzir o sujeito doente à normalidade, e a responsabili idade da doença passou a recair na maior ou menor suscetibilidade individual diante das tensões sociais. Desta forma, as conflitos existentes na sociedade e os interesses que perpassam a medicina, enquanto uma produção social, foram sempre ignorados (Minayo, 1998) .

Fm síntese, houve uma organização sintânica dos discursos médico e psicológico em prol da demanda, advinda das condições históricas do contexto modemo, de que a ciência seria responsável por promissoras mudanças na vida do ser humano em sociedade. Nesta trama disarsiva, inscreveram-se várias práticas sociais voltadas para a infância.

Levando em consideração que estamos entre o passadb e o futuro e que, assim situadas, podemas tecer uma análise crítica de nossos tempos, pela via da historicidade, é extremamente relevante, para a produção do conhecimento que se volta para essa etapa do ciclo vital, um estudo crítico acerca do efeito dessas inscrições nas práticas sociais.

Nessa perspectiva, Ferreira (1999) traz para a discussão uma indagação que atinge profundidade ao remeter para o campo da ética a relação existente entre conhecimento e prática social. A autora tece suas considerações a partir de um caso histórico, que ficou conhecido como o do "Selvagem de Aveyron". Como se sabe, Itard, médico e ecucador do menino "selvagem", discordou do diagnóstico de Pinel, que considerou Victor um "idiota incurável", e tentau reverter as privações sociais e allturais, às quais a criança fora submetida.

A autora enfatiza, então, que independentemente dos resultados obtidos por Itard nesse empreendimento, a discordância classificatória entre Itard e Pinel produziu um efeito na vida de 
Victor. Eque, na atualidade, essas discordâncias, embora muitas vezes apresentem-se respaldadas por "sofisticados avanços tecnológicos" , para viabi i izar os diagnósticos diferenciais, trazem, em seu ceme, questões aparentemente simples, tais como "o que é uma criança?" , "como se constituem sua subjetividade e seu corpo?" , "b que são as psicopatologias?", "o que é a normalidade?"

Banks-Leite e Galvão (2000) destacam o interesse que suscitam, ainda hoje, as relatórios de J. Itard, nos quais o próprio autor aponta seu fracasso na educação de Victor. O valor desses escritos reside, fundamentalmente, nas possibilidades de discussões epistemológicas em torno de eixos que persistem ainda em aberto, a saber, a relação entre o hereditário e o adquirido, a aquisição da linguagem oral e da escrita, a relação entre natureza e cultura/civilização, entre autros. Tais temas, bastante controversos, demonstram que a questão "o que é uma criança?" permanece sem respostas conclusivas.

Ferreira (1999) conclui seu trabalho apontando para o fato de que as descrições de uma determinada realidade, em relação aos comportamentas patológicas, às nosologias e às intervenções são culturalmente determinadas, pois são produtas de práticas lingüísticas, possíveis emum determinado momento histórico. Essa "determinação", porém, é sempre relativa, uma vez que, considerando um mesmo contexto sociocultural, constatam-se diferenças nas descriçães, dado que cada descrição serve a um determinado propósito. 
Tal suposição, a de que as constnuçães teóricas servema diferentes propósitos e que, por conseguinte, subsidiam práticas sociais diferenciadas, é um ponto relevante e inovador no debate epistemológico, pois, como já se indicou, conduz ao campo da ética. Desse modo, troca-se a busca "da verdade", a busca da causa última, por uma concepção ética que questiona esses propásitos, que analisa o efeito, as implicações que o saber produzido no campo da ciência podem provocar na subjetividade dos sujeitos.

\section{O EFEITO DO SABER MÉDICO-PSICOLÓGICO NAS PRÁTICAS SOCIAIS VOLTADAS PARA A INFÂNCIA}

"As práticas sociais engendram damúnios de saber que não samente fazem aparecer novos objetos, novos conceitos, novas técnicas, mas também nascer formas totalmente novas de sujeitos e de sujeitos de conhecimento" M. Foucault

O discurso social produzido pelo acolhimento e infilt ração das formações disarsivivas científicas, pelas e nas relações cotidianas dos sujeitos, quando se volta para a infância merece uma atenção cuidadosa. Esta observação leva em consideração a posição do infans como um sujeito ainda inconstituŕdo, em fase de conquista de sua subjetivação que, por sua vez, se fará a partir de uma inscrição nesse mesmo discurso social, conforme aponta Vorcaro (1999) .

Esta afirmativa, na verdade, denota uma concepção de infância extraída da psicanálise", bem como das teorias sócio-histórica e psicogenética sistematizadas por Vigotsky e hallon, demarcadas suas respectivas diferenças. Tais teorias pressupõem a construção do sujeito a partir da presença de um outro. Assim, adotam como paradigma, com ancoramento na dialética, a concepção de um sujeito dialógico e alteritário que constitui sua subjetividade no âmago mesmo da relação com o outro; por meio deste movimento relacional, serão criadas, para o infans, as possibilidades de acesso ao campo da linguagem e, por conseguinte, ao registro do simbólico.

Uma das diferenças fundamentais entre as teorias vigotskiana e walloniana e a psicanálise é que, para esta última, a constituição do sujeito se dará no seio da cena edipiana, marcada por entraves subjetivos e conflitos que decorrem da angústia que perpassa todos as personagens da cena edípica, em face das inevitáveis separaçães que marcam o percurso do Édipo. 
Portanto, para a teoria psicanalítica, a assunção de um sujeito é uma conquista intra e intersubjetiva, em que os desejos dos personagens da cena edipiana, em virtude das questões narcísicas, operam de forma contraditória na criação de possibilidades da assunção do stjeito.

Freud, em Sobre o narcisismo: Uma introolução (1914), indica que as pais, ao educarem, não se preocupam exclusivamente com o bem da criança, istoé, suas intenções não seriam tão "puras" neste empreendimento. Como filtho, a criança ocupa um lugar no desejo das figuras parentais, lugar este que é sempre alienante, já que a criança comparece para os pais como um objeto de compensação narcísica.

Apoiando-se nessa concepção e estabelecendo uma crítica aguda às práticas sociais de educação da atualidade e, por extensão, aos disarsas pedagógicas e psicológicas que as subsidiam, Lajonquière (1996, 1999, 2000) delineia sua tese acerca da renúncia ao ato educativo mediante a diluição da diferença entre a posição do adulto e a da criança, que atinge seu ápice nas práticas sociais da educação contemporânea.

Lajonquière (1996) ressalta que, embora Freud tenha considerado a criança, enquanto fonte de investimento narcísico, um universal psíquico trans-histórico, é apenas com o advento da modernidade que ela passa a ocupar o lugar de ideal e de destaque no imaginário social, pois é neste contexto, em especial, que a criança é posta em um lugar de esperança narcísica. O au- 
tor aponta para o fato de que o homem moderno, cuja referência é o futuro, e que se vê livre para imaginar, não pode abrir mão da idealização ao educar, visto que qualquer desvio deste lugar idealizado pode ameaçar a i lusão de que a criança que se educa venha a ser, futuramente, um ser perfeito, sem faltas.

Essa i lusão, por sua vez, irá aniquilar a dialética temporal na medida em que o passado passa a ser ignorado, pois o que se visa com a educação é, sobretudo, a superação da história parental. Nesta perspectiva, o presente educativo opera em torno da certeza advinda dos saberes psicológicos prescritivos do "como fazer" para potencializar o que reside de "natural" na criança.

A concepção de criança que atravessa esse tịpo de renúncia ao ato educativo está alicerçada, então, na psicologia, que concebe o indivíduo (uno) como um somatório das categorias bigpsicassociais, e estas "naturalmente" se somarão, uma vez que a categoria "bio" dará o suporte natural, por meio do processo maturacional, à "entrada" das outras categorias. Desde este panto de vista, a interação de fatores que vão se somando no processo de desenvolvimentopossibi 7 itaria, então, a constituição do indivíduo pleno, na idade adulta, em termos de suas capacidades psicológicas. Para o autor, a perspectiva natural izante aparece no discurso (psico)pedagógico hegemônico por meio da seguinte fórmula: as intervenções pedagógicas, para serem pertinentes, devem levar em conta o nível do desenvolvimento das capacidades psicológicas da cri- ança, que têm por base um curso natural.

Em resumo, tem-se, de um ladb, um investimento narcísico idealizado por parte daquele que educa e, de outro lado, um saber psicológico prescrevendo um "bem educar" que é sempre permissivo, no sentido de respeitar o processo natural da infância. Para o autor, é nesta configuração que se opera a renúncia ao ato educativo, ancorada na ilusão de criar uma criança afetivo-cognitiva ideal e de demarcar as diferenças no mundo adulto-criança também de forma ilusória e imaginária, já que esta diferença não se estabelece como uma promessa para a criança ser para além do que é ela mesma. Assim sendo, não se instaura a falta, que é condição para a assunção do desejo e, conseqüentemente, da singularidade e da verdadeira diferença.

Arendt (1972), em seu ensaio sobre a crise da educação no contexto norte-americano, na década de 50, discute, também, os paradoxos que se inscrevem na modernidade e que assolam a tarefa educativa da denominada criança escolar. Em suas discussões iniciais, a autora assinala que, embora estivesse apontando problemas específicas e confinados às fronteiras históricas de um determinado país, nada impediria que em um futuro previsível e próximo estes mesmos problemas relacionados ao campo educativo pudessem acometer, igualmente, qualquer outranação.

Nessa perspectiva, ao se analisar os apontamentos da autora e compará-los aos problemas encon- 
trados no contexto educacional atual, no Brasil, pode-se destacar a pertinência dos seguintes pontos de suas formulações:

- a educação assume um caráter permanente de crise e, desta forma, atrela-se à i lusão do pathos do novo, ou seja, sob a divisa de uma educação progressista, de um momento ao outro novas teorias ganham rapidamente terreno e solapam toola a tradição e os métodos de ensino e de aprendizagem que estavam sendo, anteriormente, aplicados;

- em virtude da constante ruptura coma tradição e apoiada nas respostas encontradas nessas teorias, a autoridade é recusada pelos adultos. Tal recusa gerou algumas conseqüências, quais sejam: as crianças emanciparam-se dessa autoridadee, por conseguinte, desdbrigaram-se de alçar ao mundo adulto. Ficaram, então, entregues à tirania do próprio mundo infantil e deixaram de se fami liarizar com as exigências de um mundo em contínua mudança;

- no âmbito escolar, sob a influência da psicologia, a pedagogia tornou-se uma ciência de ensino geral e o conhecimento aprofundado das matérias específicas deixou de ter importância para o ato de ensinar. Isto resultou em um negligenciamento na formação dos professores, no que tange aos campos de saberes específicos. Como efeito imediato desse redimensionamento em prol do pedagógico e em detrimento da educação, os alunos deixaram de ter a fonte legítima de autoridade pela via do conhecimento, que é o professor, ficando entregues a seus próprios rearrsos. 
Para Arendt (1972) , a crise da educação estabeleceu-se pelos paradoxos surgidos no mundo moderno. A educação, por sua própria finalidade, não pode abrir mão da autoridade, tampouco da tradição; todavia, esses dois atributos foram postos em xeque no contexto da modemidade. Uma outra contradição permeia a questão da temporalidade: o ato educativo, para ser, de fato, legítimo, sempre deve se voltar para o passado, pois cabe ao educador ensinar à criança como o mundo é, e não ensiná-la a viver no futuro. Assim, para a autora, "a qual ificação do professor consiste em conhecer o mundo, responsabilizar-se por ele e ser capaz de instruir as outros acerca deste. Em face da criança, é como se ele fosse um representante de todos as habitantes adultos, apontando os detalhes e dizendo à criança: isso é o nosso mundo" (p. 239) .

Pode-se concluir, então, que se tem, na atualidade, um arcabouço teórico-prático ancorando as premissas educativas no qual as teorias da psicologia muito contribuem com uma visão que hipervaloriza os impasses que o indivíduo vivencia em sua escolarização, esvaziando, simultaneamente, a própria finalidade da educação. Finalidade que seria a de produzir efeitos humanizantes para o aprendiz, inserindo-o no mundo da cultura, por meio da fórmula aparentemente simples: "Quem sabe ensina, quem não sabe aprende" (Iajonquière, 1999) .

Como efeito do excesso de psicologização no sistema escolar, a prática educativa prende-se à fixidez do ideal e o ato pedagógico opera no sentido de fazer com que o conhecimento fique circunscrito a um lugar, ao qual só se pode ter acesso na medida em que, antecipadamente, o aluno dê provas de sua capacidade para aprender. Este deve, assim, estar apto e "pronto" do ponto de vista cognitivo, cultural e relacional. Opera-se, dessa forma, uma inversão do papel do educador, ao qual, antes de tudb, cabe ensinar, para que se criem as possibilidades do aprender (Legnani \& Almeida, 2000).

Tendo em vista o fato de que o conhecimento especializado de cada área deixou de ter a devida importância para a educação, como indica Arendt (1972), atualmente, os educadores ocupam uma posição marcada pela opacidade e pelo mal-estar, tenob dificuldades de sustentar a função educativa no que conceme à transmissão do conhecimento. Cabe à psicologia, com seus "saberes científicos" acerca do desenvolvimento humano e da subjetividade do indivíduo, e não mais aos fundamentos intemos de cada disciplina, consubstanciar, ilusoriamente, a dicática do ato pedagógico.

Uma das manifestações do mal-estar dos educadores é a busca voraz de teorias psicológicas passíveis de serem transformadas 
em "métodos didáticos rápidos e eficazes" para combater as problemas educacionais. Há sempre um imediatismo que assola os cursos de formação de professores, o qual se respalda na adoção de uma postura acrítica de que é possível transformar teorias em soluções mágicas (Collares \& Moysés, 1996) .

Desse modo, não é raro encontrar instituições educacionais presas a discursos cristalizados perpassadas pelo sentimento de impotência e paralisia diante das problemáticas dos alunos. Tal paralisia, por sua vez, suscita as queixas escolares em tomo das crianças consideradas diferentes e os inúmeros encaminhamentos dos desviantes aos profissionais das áreas médica, psicológica e psicopedagógica.

Para concluir esta breve análise dos problemas que atravessam o campo educacional brasileiro, faz-se necessário salientar que, em virtude da complexidade da crise desse sistema, qualquer análise feita será sempre parcial. Portanto, a questão que focaliza o baixo nível de conhecimento transmitido, após a quebra da tradição do ensino, é apenas um dos fatores que têm produzido desordenamento no contexto da escolarização. Desordenamento este que produz implicações que não podem ser desconsideradas, pois favorece um discurso dos educadores marcado pelo gozo, na medida que em estes passam a falar de uma posição "sem saída", respaldados pelo excesso de psicologização existente hoje em dia no ambiente escolar.

É em tomo dessa pasição "sem saída" que collares e Mbysés (1992) demonstram que o sistema educacional, ao atribuir causalidade aos altos índices de reprovação e evasão escolar, vinaula suas explicaçães a pretensas dbenças, que, muitas vezes, não têm validação empírica alguma. O processo de biologização do social cumpriria a função de apaziguamento dos conflitos e, tal como a psicologização, geraria um descompromisso das instituições escolares diante da problemática dos alunos, por meio da medicalização do processo de ensino e aprendizagem.

Conforme já apontado, o discurso médico respalda-se em uma concepção biologizante sobre a relação doença/saúde e, conseqüentemente, constrói suas explicações e descrições dentro deste parâmetro. A particicipação dos fatores psicológicos e sociais, quando admitida, gera, normalmente, análises compartimentadas e estanques, pois prepondera a concepção de que, na existência de um problema orgânico de origem, o desenvolvimento das patologias pode vir a ser potencial izadb, caso os estímulos ambientais não sejam adequados e pertinentes.

Nessa visão, busca-se a disssolução da dicotomia biológico versus psíquico mediante explicações hîbridas acerca da etiologia 
das patologias, conforme destaca Kupfer (1996) . Para Coriat (1997) , atualmente, no anseio de viabilizar a dissolução dessa antinomia e inconporar uma concepção holística sobre o ser humano, os organicistas e os psicologistas reconhecem a importância de ambos os fatores como se houvesse uma adição de causas para o surgimento das patologias. Esse scmatório, contudo, não leva em consideração a forma com que tais fatores se combinam e se articulam, gerando, assim, uma produção disarsiva superficial e sem fundamentação lógica.

Como essas explicações alicerçam-se no hibridismo epistemológico e comparecem de forma desarticulada nas explicaçães das problemáticas psíquicas, o que prepondera nas descrições quando transpostas, por exemplo, para a prática educativa, é a demarcação de uma etiologia orgânica. Deste modo, as práticas sociais de educação inconporam o foco desse discurso sem criticidade, pois entendem que tais formaçães discursivas são construídas com a chancela de um conhecimento médico, que é cientificamente comprovado.

Tanto Kupfer (1996) quanto Coriat (1997) tecem uma análise histórica das terminologias e descrições médicas, as quais, atreladas a uma visão linear de causa e efeito, postularam sempre uma causalidade orgânica e/ou genética nas explicações acerca das dificuldades de aprendizagem. Como conclusão, assinalam que o sistema educacional inconpora, como verdade, mitificações cientificizadas, tanto da área médica quanto da psicológica, gerando, assim, o fenômeno da psicopatologização das dificuldades infantis. As autoras propõem à educação, como desafio, a tarefa de retomar seu próprio campo de conhecimento, seja no âmbito teórico, seja no da atuação no cotidiano da sala de aula.

\section{A NOVA FACE DO FENÔMENO DE BIOLOGIZAÇÃO DOS PROBLEMAS PSÍQUICOS DA INFÂNCIA}

Ná atualidade, respaldado pelo avanço da psiquiatria biológica das duas últimas décadas, o discurso médico insere-se numa concepşão biologizante, na qual a psicofarmacologia e as neurociências tomaram-se um fato de mídia, como assinala Bogochvol (2001) . O autor aponta para o fato de que as atividades de pesquisa ligadas à neurobiologia e à psicofarmacologia impressionam tanto em termos científicos como em termos econômicos. Muito se gasta em pesquisas, desenvolvimento de tecnologias, 
testes, divulgação e marketing. As informaçães são difundidas e incorporadas, pelo sistema de crenças socialmente compartilhadas, como verdades cientificamente provadas. "É parte do senso comum contemporâneo a idéia de que várias formas de sofrimento, de mal-estar, de distúrbios psíquicos são causadas, tratadas e curadas biologicamente" (Bogochvol, 2001, pp. 36-7) .

Para além do apaziguamento das problemáticas sociais, esta nova biologização, dentro da lógica arativa, gera um descompromisso subjetivo diante das vicissitudes da existência humana. Lógica presente em maior ou menor grau - nos diversos transtomos diagnosticados pela primeira vez na infância ou na adblescência, a saber: Transtomos Invasivos do Desenvolvimento, Transtomos de Conduta, Transtornos das Habilidades Escolares, Transtomos Alimentares, Transtornos de Humor (terminologia adotada pelo DSM IV, 1995). Tal lógica se evidenciará, sobretudb, na descrição diagnóstica do Transtomo de Déficit de Atenção e Hiperatividade $(T D A / H)$.

Na época atual, esse diagnóstico constitui a descrição médica mais ut 1 l izada para dar vazão ao mecanismo de psicopatologização das difiauldades das crianças no processo de escolarização. Assim, essa "dbença neurológica" do aluno opera, a priori, de forma reconfortante para a escola, na medida em que a isenta, mesmo que parcialmente, da responsabilidade sobre o desempenho escolar db aluno. Nesta perspectiva, a escola demanda e acolhe as orienta- 
ções médico-psicológicas para circunscrever um lugar para a criança com diagnóstico de TDA/H. Tentase uma padronização dos sujeitos, ancorada na premissa médica de um déficit neurológico que, supostamente, homogeneizaria essas crianças. Na visão dos professores, tais orientaçães são necessárias para sustentar uma prática pedagógica didaticamente planejada para lidar com os difíceis, impulsivos, desatentoseturbullentos alumos. O preço deste planejamento, no entanto, não é consideradb: a destituição da passibilidade de cada um encontrar seu lugar no mundo, impassibil itando que a criança com diagnóstico de TDA/ H venha a ocupar o lugar de sujeito em seu processo de escolarização.

Nessa direção, a instituição escolar inconpora o discurso médico e propaga o ideário do déficit, como aponta Lajonquière (2001), concebendo-o como uma falta a ser apagada. Seguindo esta conceppcão, as encaminhamentos (psico) pedagógicos inclusivos enfatizamas técnicas e os métoobs capazes de suprimir tais deficiêrcias.

Por conseguinte, ao propor as premissas inclusivas nesses parâmetros, a escola demanda dos educadores uma postura calcada na caridade. Desde este ponto de vista, o aluno estaria em uma posição de inferioridade em relaçãa aos demais. Sua diferença é constantemente reafirmada, e ele não é visto como um igual, como um sujeito, sua alteridade não sendo reconhecida. Apenas a diferença, apontada pelo diagnóstico, em termos de incapacidade, causada por um quadro congê- nito, genético au adquirido, é incorporada pela escola. A diferença de uma criança, enquanto um outro com uma relação própria com a palavra, é negada, não é incluída neste contexto.

Desse modo, o educador não legitima a palavra dita pela criança para que o simbólico se subjetive e, ao não autenticar essa palavra, deixa-a mais uma vez entregue ao gozo conporal, por meio da hiperatividade. De um outro modo, deixa de transmitir o conhecimento, de forma efetiva, para o aluno diferente, impedindo que ele possa, a partir do saber já estabelecido, construir algumas marcas e referências acerca da noção de tempo, espaço e causalidade, bem como significar as objetos com base em convicções socialmente partil hadas. Estes organizadores são fundamentais para que a criança possa verificar o que the escapa, a seja, possibil itam-Ihe saber o que ainda não sabe, diluindo, assim, sua dificuldade de concentração.

É de suma relevância que a educação escolar redimensione as possibilidades e condiçães de inclusão da criança a jja posição subjetiva revela-se nas manifestações sintomáticas do TDA/H, de forma que the sejam proporcionados maior autonomia de pensamento e controle de suas ações e relações.

A função da escola, no entanto, cumpre-se pelo avesso, ao enredar, ainda mais, na via da alienação, a posição desse sujeito. Por attro ladb, as esclarecimentas científicos e as orientaçães recebidas dos especialistas parecem tão-scmente aturdir os 
educadores em relação ao que fazer. Aturdimento que retira o valor simbólico das palavras, no contexto escolar, que passa a funcionar sob a forma de ato diante da criança turbulenta; esta, sem saída, responde de igual forma: atuandb.

Para concluir, ressalta-se, aqui, que a sigla diagnóstica de TDA/H, ao ser cunhada nos alumos, produz, como efeito, a exigência de participação de vários profissionais no atendimento à criança. Neste sentido, constitui-se, também, como um modelo de entendimento dos impasses que comparecem nas denominadas equipes interdisciplinares.

Com freqüência, encontram-se especialistas da área da saúde que desconhecem as causas históricas, políticas e sociais das inúmeras queixas escolares que hoje são fabricadas no interior das escolas. Em virtude deste fato, os diagnósticos médicos/ psicológicos que retornam à escola, quando desprovidos do devido cuidado ético, ratificam os mecanismos excludentes de isenção da responsabilidade educativa, que ainda imperam no sistema escolar.

De igual forma, os professores têm dificuldades para avaliar criticamente os laudas psicológicas e/ou as laudos médicas emitidos sobre as alunos, tomando-as, muitas vezes, como uma "verdade" absoluta. Acredita-se, a partir dos impasses vivenciados na prática clínica com essas crianças, que tais dificuldades persistem devido a uma ausência de questionamento crítico acerca dos determinantes históricos e dos fundamentos epistemológicos das teorias e dos eixos metooblógicos nos quais assentam-se as avaliaçães diagnósticas.

Ancorando-se nesse entendimento, a intervenção do psicanalista não pode deixar de focalizar e analisar os efeitos das relações institucionais e sociais do ambiente escolar na posição subjetiva da criança diagnosticada. É recomendável, portanto, um redimensionamento do modelo clínico tradicionalmente adotado, que entende a terapêutica apenas como um encontro com a criança, no qual se visaria à elaboração da verdade aludida pelo sintoma. Nesse modelo subjaz a concepção de que a dinâmica familiar, introjetada pelo pequeno sujeito, deve se constituir no alvo da intervenção analítica.

Embora essa visão venha se modificando, ainda persistem impasses e dúvidas em tomo das tentativas de se responder às questões da seguinte ordem: o que pode fazer um analista para viabilizar a inclusão de uma criança autista, psicótica ou com o diagnóstico médico de TDA/H na escola?

Sabe-se, desde Freud, que a possibilidade de significação subjetiva só se constrói pela própria fala, endereçada a um outro, 
que ocupa, transferencialmente, um lugar diferenciado. Assim, considerandb os disarsos instituŕdos e instituintes que perpassam a rede de relações do sistema escolar, é pelo próprio discurso que o professor pode vir a se beneficiar dos efeitos de significação acerca de suas frustrações, anseios e expectativas na atuação com os alunos que comparecem com alguma diferença.

Dito de outro modo, de um analista, nas suas relações coma escola, espera-se que ele possa escutar o sentidb das falas, deixando de ladb o saber toob, por ser este um saber acima sobrea instituiçãoe, por conseguinte, acima dos sujeitos, como indica Stazzone (1997). Portanto, para que haja circulação do discurso institucional, impedindo-o de cristalização, é imprescindível que o analista faça uma escuta das diversas "vozes institucionais", calandbse em relação a seu próprio desejo, evitando as prescrições e operando de modo que contribua com o educador na reversão da situação de exclusão da criança no sistema escolar.

Assim, cabe ao analista transpor a fragmentação das intervençães clínicas/educativas resultantes das diferentes respostas às questões - 0 que é uma criança? o que se trata, em uma criança? - e abrir um espaço diferenciado de reflexão e de escuta junto à equipe interdisciplinar. Em atras palavras: cabe ao psicanal ista assegurar o propósito ético das práticas sociais, em educação, que é o de ratificar a dimensão do sujeito, que persiste qpaca sob as siglas diagnósticas, de forma tal que não se apague nem se di lua ainda mais, pos- 
sibil itandb, assim, que a criança tenha chances de conquistar sua subjetivação por meio da assunção à sua própria palavra.

\section{REFERÊNCIAS BIBLIOGRÁFICAS}

Arenat, H. (1972). Entre o passadb e o futurro. São Paulo, SP: Perspectiva.

Ariès, P. (1981) . História social da criança eda famí7ia. Rio de Janeiro, RJ: Guanabara.

Banks-Leite, L. \& Galvão, I. (2000) . Uma introdução à história de Victor de Aveyron e suas repercussões. In L. Banks-Leite \& I. Galvão (orgs.) . A educação de um selvagem. As experiências pedagógicas de Jean Itard. São Paulo, SP: Cortez, pp. 11-24.

Birman, J. (1997) . Estilo e modemidade em psicanálise. São Paulo, SP: 34.

Bogochvol, A. (2001). Sobre a psicofarmacologia. In M. C. R. Magalhães (org.) . Psicofarmacologia e psicanálise. Sáo Paulo, SP: Escuta, pp. 35-61.

Castro, L. R. de (1992). Desenvolvimento humano: Uma perspectiva paradigmática sobre a temporalidade. Psicologia: Reflexão e Crítica, 2 (5) , pp. 99-110.

(1996) . O lugar da infância na modemidade. Psicologia: Reflexão e Crítica, 9 (2) , pp. 307-35.

Cauvilla, W. (1999). Sobre um momento da constituição da idéia de infância: Ponto de vista de um historiador. Esti los da Clínica: Revista sobre a Infância com Problemas, IV (6) , pp. 72-9.

Collares, C. A. L. \& Mbysés, M. A. A. (1992) . A história não contada dos problemas de aprendizagem. Cademos CEDES, 28, pp. 31-47.

(1996) . Precanceitos no cotidiano escolar: Ensino emedicalização. São Paulo, SP: cortez.

Coriat, E. (1997) . Causas e acasos. Estilos da Clínica: Revista sobre a Infância com Pro- blemas, III (3), pp. 8-14.

Costa, J. F. (1989) . Ordem médica e norma fami7iar. Rio de Janeiro, RJ: Graal.

DSM IV (1995) . Manual diagnóstico e estatístico de transtomos mentais. Porto Alegre, RS: Artes Médicas.

Ferreira, C. M. P. (1999) . Considerações sobre o autismo e suas passíveis causas. Revista de Psiquiatria e Psicanálise com Crianças e Adblescentes. Centro Psicopedagógico/FHENIG, II (8) , pp. 75-85.

Freud, S. (1914) . Sobre o narcisismo: Uma introdução. In Edição standard brasi leira das doras completas de Sigmud Freud (J. Salonão, trad.) (Vol. 14) . Rio de Janeiro, RJ: Imago, 1980.

Julien, P. (2000) . Abandbrarás teupai e tuamãe. Rio de Janeiro, RJ: Companhia de Freud.

Kupfer, M. C. (1996). Psicose e autismo na infância: Problemas diagnósticos. Estilos da Clínica: Revista sobre a Infância com Problemas, V (7) , pp. 96-107.

Lajonquière, L. de (1996). A criança, "sua" (in) disciplina eapsicanálise. In J. G. Aquino (org.) . A indisciplinana escola: Altemativas teóricas epráticas. São Paulo, SP: Summus, pp. 25-38.

(1999) . Infância e ilusão (psico) pedagágica. Petrópolis, RJ: Vozes.

(2000) . O que da infância a ilusão (psico) pedagógica mascara. Esti los da Clínica: Revista sobre a Infância com Problemas, V (8), pp. 183-9. (2001) . Duas notas psicanalíticas sobre as crianças "com necessidades educativas especiais". Pro-Posições. 12 (2/3) , pp. 47-59.

Legnani, V. N. \&Almeida, S. F. C. (2000) . A idealização do ato educativo: Efeitos no fracasso escolar das crianças das camadas populares. Estilos da Clínica: Revista sobre a Infância com Problemas, V (8), pp. 94-111.

Minayo, M. C. de S. (1998) . O desafio do conhecimento: Pesquisa qualitativa em.saúde. São Paulo, SP: Hucitec/Abrasco. 
Muller, T. M. P. (1999). Creanças anormaes: Tratamento e ecucação na Primeira República. Revista de Psiquiatria e Psicanálise cam Crianças e Adblescentes. Centro Psicopedagógico/FHEMIG, II (8) , pp. 9-21.

Pilotti, F. \&\&izzini, I. (orgs.) (1995). Aarte de govemar crianças. Rio de Janeiro, RJ: Instituto Interamericano del Niño/Editora Santa Úrsula/Amais.

Rizzini, I. (org.) (1997) . Olhares sobre a criança no Brasil - Sécullos XIX eXX. Rio de Janeiro, RJ: USU/Universitária/Amais.

Stazzone, R. (1997). O que deve fazer um psicanalista na escola? Esti los da Clínica: Revista sobre a Infância com Problemas, II (2) , pp. 44-52.

Vorcaro, A. (1999) . Crianças na psicanálise: Clínica, institurição, laçosocial. Riode Janeiro, RJ: Companhia de Freud.

NOTAS

1 Este trabalho é uma versão, modificada, extraída da tese de doutorado Transtomo de déficit de atenção e hiperatividade: Umestuob de psicanalítico, 2003, UnB, de autoria de Viviane Legnani, sob a orientação de Sandra F. C. de Almeida.

2 Segundo Rizzini (1997) , o discurso higienista atingiu tanto a esfera privada quanto a esfera püblica. Para a primeira, estipulou as regras do modo de viver (alimentação, vestuário, etc.) . Em relação à higiene pública, as propostas higiênicas terão penetração em inúmeros aspectos da vida social. Segundo a autora, várias teses médicas, publicadas nessa época, terão propostas para higienizar a infância, os loucos, os pobres, as mulheres, como também as instituições: hospitais, hospícios, quartéis, asilos, escolas.

3 Título do ensaio fil losófico de Harnah Arendt, publicado originalmente em 1954.
${ }^{4} \mathrm{Na}$ leitura de Biman (1997) , a concepção de uma subjetividade dialógica, embora presente nas formulações freudianas, começará a ter ummaior espaço na teoria psicanalítica a partir das sistematizações de Politzer, bem como a partir das formulações de Ricour, que propõe a inscrição da psicanál ise nas ciências da cultura, e, sobretudb, do trabalho de Lacan, na medida em que este introduz em suas formulações as sistematizações filosóficas de Hegel.
Recebiob em abril/2004. Aceito emmaio/2004. 